\title{
Atomic Structures of the 30S Subunit and Its Complexes with Ligands and Antibiotics
}

\author{
D.E. Brodersen, A.P. Carter, W.M. Clemons, Jr., R.J. Morgan-Warren, \\ F.V. Murphy IV, J.M. OGLe, M.J. TARRY, B.T. Wimberly, and V. RAMAKRISHNAN \\ MRC Laboratory of Molecular Biology, Cambridge CB2 2QH, United Kingdom
}

The two subunits that make up the ribosome have both distinct and cooperative functions. The $30 \mathrm{~S}$ ribosomal subunit binds messenger RNA (mRNA) and is involved in the selection of cognate transfer RNA (tRNA) by monitoring codon-anticodon base-pairing during the decoding process. The $50 \mathrm{~S}$ subunit catalyzes peptide-bond formation. Both subunits work in concert to move tRNAs and mRNAs relative to the ribosome in translocation, and both are the target of a large number of naturally occurring antibiotics. Thus, useful information about the mechanism of translation can be gleaned from structures of both individual subunits and the intact ribosome. In this paper, we describe our work on the determination of the atomic structure of the $30 \mathrm{~S}$ ribosomal subunit and its complexes with RNA ligands, antibiotics, and initiation factor IF1. The results provide structural insights into how the ribosome recognizes cognate tRNA and discriminates against near-cognate tRNA. They also provide a structural basis for understanding the action of various antibiotics that target the 30 S subunit.

Knowledge of the atomic structure of the $30 \mathrm{~S}$ is the culmination of decades of work on its structure and function. The state of the ribosome field two years ago has been summarized in a recent book (Garrett et al. 2000). The initial breakthrough in the goal toward a crystal structure of the ribosome was the crystallization of 50S subunits suitable for diffraction studies by Yonath and coworkers (Yonath et al. 1980). Although these original crystals did not diffract very well, over the course of several years, improved crystals of the $50 \mathrm{~S}$ subunit were obtained that eventually resulted in diffraction to $3 \AA$ resolution (von Böhlen et al. 1991). Another important advance was the introduction of cryocrystallography to facilitate data collection (Garman and Schneider 1997). Following the demonstration by Hope that cryocrystallography could significantly reduce radiation damage on various proteins (Hope 1988), Hope, Yonath, and coworkers showed that it also reduced damage to ribosome crystals (Hope et al. 1989). Even if better crystals had been obtained in the early 1980s, the technology available then was insufficient to determine the structure of a ribosomal subunit to high resolution. Important developments in synchrotron X-ray sources, instrumentation, and computation (Helliwell 1998; Hendrickson 2000) were all essential for the current progress.

\section{CRYSTALLIZATION OF THE 30S SUBUNIT}

Crystals of both the $30 \mathrm{~S}$ subunit and 70S ribosomes from Thermus thermophilus that were suitable for structural studies were first reported by the Puschino group (Trakhanov et al. 1987; Yusupov et al. 1987). These crystals used 2-methyl-2,4-pentanediol (MPD) as the precipitant, and shortly afterward, crystals of the $30 \mathrm{~S}$ in a mixture of ethanol and ethylbutanol were reported by the Yonath group (Glotz et al. 1987). The $30 \mathrm{~S}$ subunit crystals in MPD diffracted to about 10-12 $\AA$ resolution initially (Yonath et al. 1988; Yusupov et al. 1988), and by 1995, their diffraction limit had only improved to about 7-8 $\AA$ resolution (Schluenzen et al. 1995). However, by that time, advances in single-particle reconstruction methods in cryo-electron microscopy had shown that the $30 \mathrm{~S}$ subunit was conformationally different in the active, inactive, and 50S-bound states (Frank et al. 1995; Lata et al. 1996). This suggested to us that conformational variability of the $30 \mathrm{~S}$ subunit could be the reason for the poor diffraction reported for its crystals, and we reasoned that, by analogy with smaller enzymes, binding of substrates or cofactors might result in complexes that were conformationally homogeneous and therefore yield better crystals.

As a starting point, we used the original crystallization conditions reported by the Puschino group. To our surprise, a straightforward optimization of the original conditions resulted in crystals that diffracted to beyond $3 \AA$ at third-generation synchrotron sources (Clemons et al. 1999; Wimberly et al. 2000). Unlike improved crystals of the 30S subunit produced by the Yonath group (Yonath et al. 1998; Tocilj et al. 1999), our crystals do not require soaking in tungsten clusters and heat treatment to result in diffraction to high resolution, and the reason they diffract so well will become apparent below.

\section{STRUCTURE DETERMINATION}

Just three years ago, it was not clear that the crystallographic phase problem could be solved for asymmetric units as large as a ribosomal subunit. It has long been known that heavy atom clusters of tungsten or tantalum could be used for obtaining phase information for large molecules (Blundell and Johnson 1976). They were used in the structure determination of large complexes such as 
ribulose biphosphate carboxylase and the nucleosome core particle (O'Halloran et al. 1987; Andersson et al. 1989; Knablein et al. 1997). The use of clusters was also suggested for ribosomes (Thygesen et al. 1996). The first concrete demonstration that such clusters could yield phase information for ribosome-sized problems came when they could be visualized directly in difference-Patterson maps of the 50S subunit and resulted in electron density maps that showed unambiguous right-handed helices corresponding to A-form RNA duplexes (Ban et al. 1998).

At the same time, anomalous scattering has seen increasing use in structure determination, especially through the use of the multi-wavelength anomalous diffraction (MAD) technique on crystals of proteins labeled with selenomethionine (Hendrickson et al. 1990; Hendrickson 1991). It was shown by us that treatment of MAD as a special case of standard multiple isomorphous replacement (MIR) resulted in excellent phases despite the nominally very small signal from anomalous scattering (Ramakrishnan et al. 1993; Ramakrishnan and Biou 1997). A test calculation shows that a fully selenomethionylated ribosome would have too little signal to be useful (Clemons et al. 2001). However, the LIII edges of many elements typically have 3-4 times the anomalous scattering of the K-edge of selenium, and were previously used for both protein (Kahn et al. 1985; Weis et al. 1991) and RNA (Cate et al. 1996) structure determination. Calculations based on the original equation by Crick and Magdoff (1956) showed that even 10-20 sites per 30S subunit would result in a measurable signal (Clemons et al. 2001), offering an alternative route to the phasing problem. This conclusion appears to have been reached independently by the various groups working on ribosome crystallography. Our atomic structure of the $30 \mathrm{~S}$, as well as that of the 50S (Ban et al. 2000) and the 70S (Cate et al. 1999), were all solved primarily using LIII edges of compounds such as osmium or iridium hexammine, although in each case, heavy atom clusters were very useful in the determination of low-resolution phases.

The structure of the $30 \mathrm{~S}$ in our laboratory was determined in two steps: Initially, a $5.5 \AA$ resolution structure was determined, which implicitly described the correct molecular packing in the crystal (Clemons et al. 1999). Even at this resolution, we were able to interpret about a third of the structure because of the large amount of prior structural and biochemical data on the 30S subunit. We were able to place proteins whose structures had been determined in isolation, deduce the fold and location of the previously unknown protein S20, and determine the fold of the entire central domain of $16 \mathrm{~S}$ RNA and the relative location of the functionally important helix 44 along the interface of the subunit.

Last year, we published the complete atomic structure of the 30S subunit (Wimberly et al. 2000). Crystallographic details of the determination of the $30 \mathrm{~S}$ structure have been published recently (Clemons et al. 2001).

\section{GLOBAL ARCHITECTURE}

The final refined atomic model of the $30 \mathrm{~S}$ subunit at 3 Å resolution contains 1513 out of 1521 nucleotides of $16 \mathrm{~S}$
RNA and all 20 polypeptide chains present in the crystal (S2-S20, THX), with $98 \%$ of the sequence built into the molecule (Wimberly et al. 2000). The missing regions occur exclusively at the termini of the RNA and proteins.

The secondary structure of Thermus $16 \mathrm{~S}$ RNA is very close to that predicted on the basis of phylogenetic comparisons (Gutell 1996), which is shown in Figure 1 along with the standard Brimacombe numbering for the various double helical elements (Glotz and Brimacombe 1980; Mueller et al. 1997). Figure 1 also indicates the insertions and deletions relative to the Escherichia coli 16S RNA sequence, and both sets of numberings are shown to aid biochemical analysis. The secondary structure domains of 16S RNA form distinct domains in three dimensions (Fig. $2 \mathrm{a}$ ), so that the $5^{\prime}$ domain forms the body, the central domain forms the platform, the $3^{\prime}$ major domain forms the head, and the 3 ' minor domain consists largely of two helices that lie on the intersubunit interface. This is different from the structure of 23S RNA, where the division of secondary structure domains appears to be more arbitrary and where the secondary structure domains are closely intertwined in three dimensions. The three-dimensional structure of 16S RNA has been described briefly (Wimberly et al. 2000), and a detailed analysis is in progress.

The shape of the $30 \mathrm{~S}$ is very similar to that seen by electron microscopy. In addition to the classic features of the head, shoulder, and platform, one can also see the "beak" and "spur" that were observed using cryoelectron microscopy (Frank et al. 1995; Stark et al. 1995). From a comparison of the various electron microscopic images of the 30S subunit (Frank et al. 1995; Lata et al. 1996), it appears that the crystal structure is closer to the 50Sbound form than to either the active or inactive conformations of the isolated subunit.

The overall shape and gross morphological features of the $30 \mathrm{~S}$ subunit are largely determined by the RNA component (cf. Figs. 2a and 2c). The RNA contains more than 50 regular helices. Many of the regions that were considered to be single-stranded loops in the secondary structure are in fact irregular extensions of regular double helices, so the molecule can be thought of in three dimensions as largely helical. Neighboring helical elements are often coaxially stacked; e.g., helices 16 and 17 in the $5^{\prime}$ domain or helices 21,22 , and 23 in the central domain. These coaxially stacked helices are packed using primarily three types of interactions, all of which use the minor groove as the packing interface (Wimberly et al. 2000). A notable feature is the use of highly conserved adenines to make tertiary interactions by binding in the minor groove of an adjacent double-helical section of RNA. As described below, this feature is also used in decoding.

The proteins mainly decorate the back and periphery of the $30 \mathrm{~S}$ subunit (Fig. 2b), whereas the interface surface consists largely of ribosomal RNA (Fig. 2c). A glaring exception to this rule is S12, which is located near the decoding site at the interface. Proteins S13 and S19 also lie mainly on the $50 \mathrm{~S}$ side of the head.

Many of the proteins have highly elongated extensions or internal loops (Fig. 3). A particularly dramatic example is $\mathrm{S} 12$, which is the only protein that lies directly at the intersubunit interface, but has a long amino-terminal 


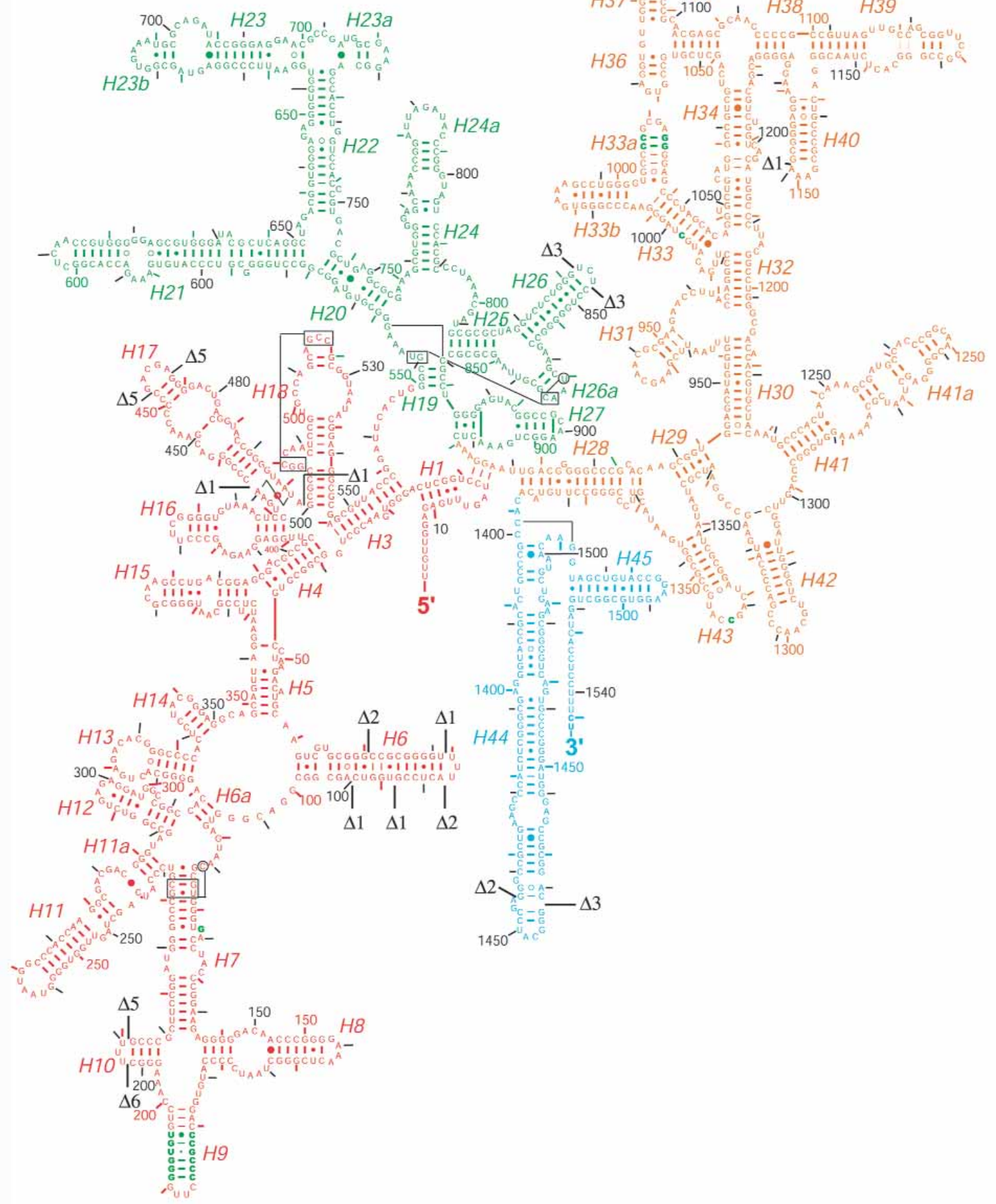

Figure 1. Secondary structure diagram of 16S RNA from Thermus thermophilus, colored by domain ( $5^{\prime}$ domain red, central domain green, 3' major domain orange, and 3' minor domain blue). Insertions in the Thermus sequence relative to E. coli occur in the $5^{\prime}$ and $3^{\prime}$ major domains and are shown in green. Deletions are indicated with black tick marks and a " $\Delta n$ " to show the deletion of $n$ nucleotides. The T. thermophilus numbering is shown by tick marks for every 10th nucleotide and labels for every 50 nucleotides, colored as for each domain. Corresponding E. coli numbering and tick marks are shown in black throughout. (Modified, with permission, from http://www.rna.icmb.utexas.edu; see Gutell 1996.)

extension that threads through the $30 \mathrm{~S}$ subunit and makes contact with S8 and S17 on the back side. In general, these extensions are highly basic, make intimate contacts with ribosomal RNA, and help with the assembly and folding of the $30 \mathrm{~S}$ subunit. Similar extensions have also been observed in the 50S structure (Ban et al. 2000). 


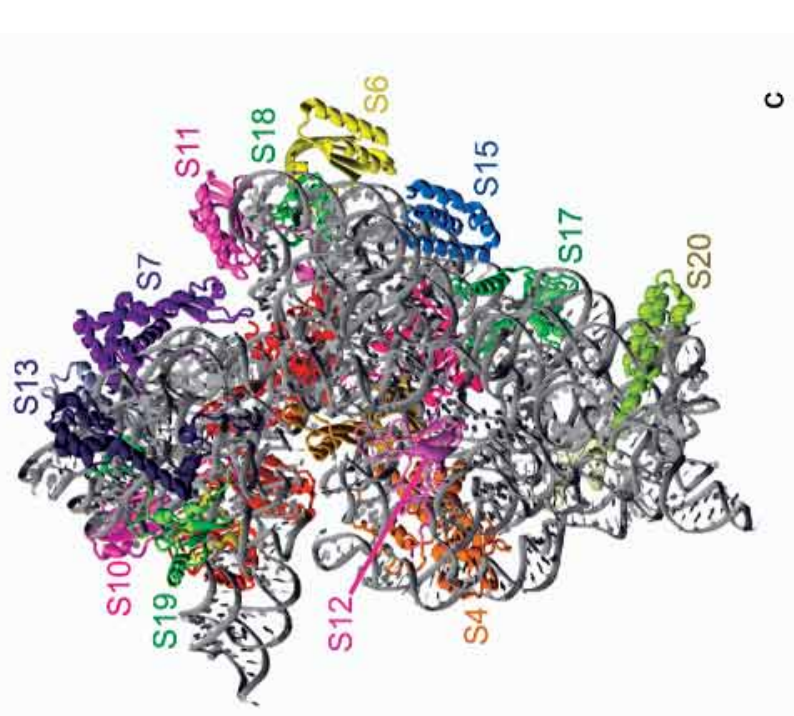

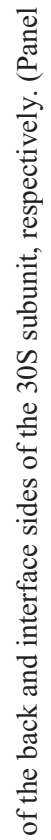
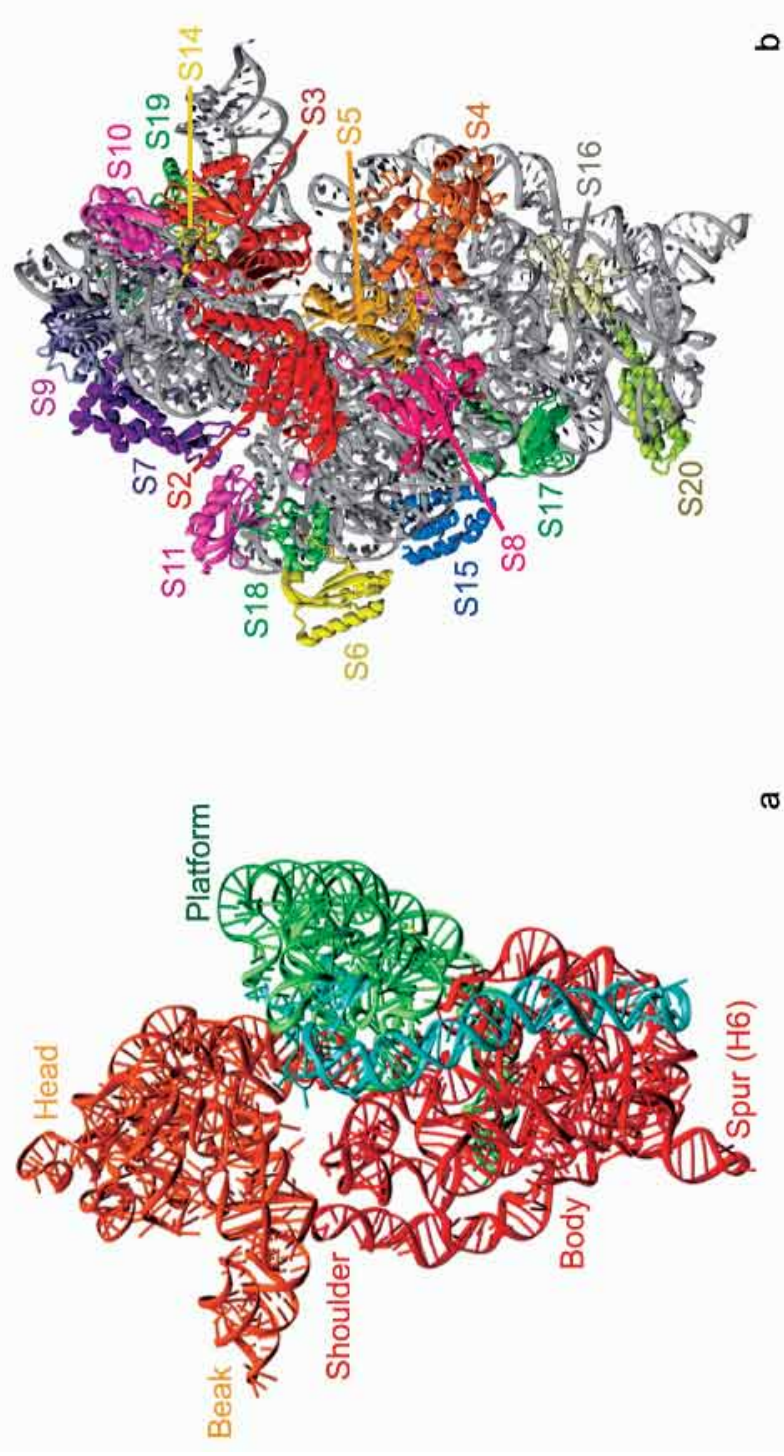

๙

哭:

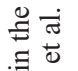

这

을

प유.

氖

की

矛造

है

i.

倍 


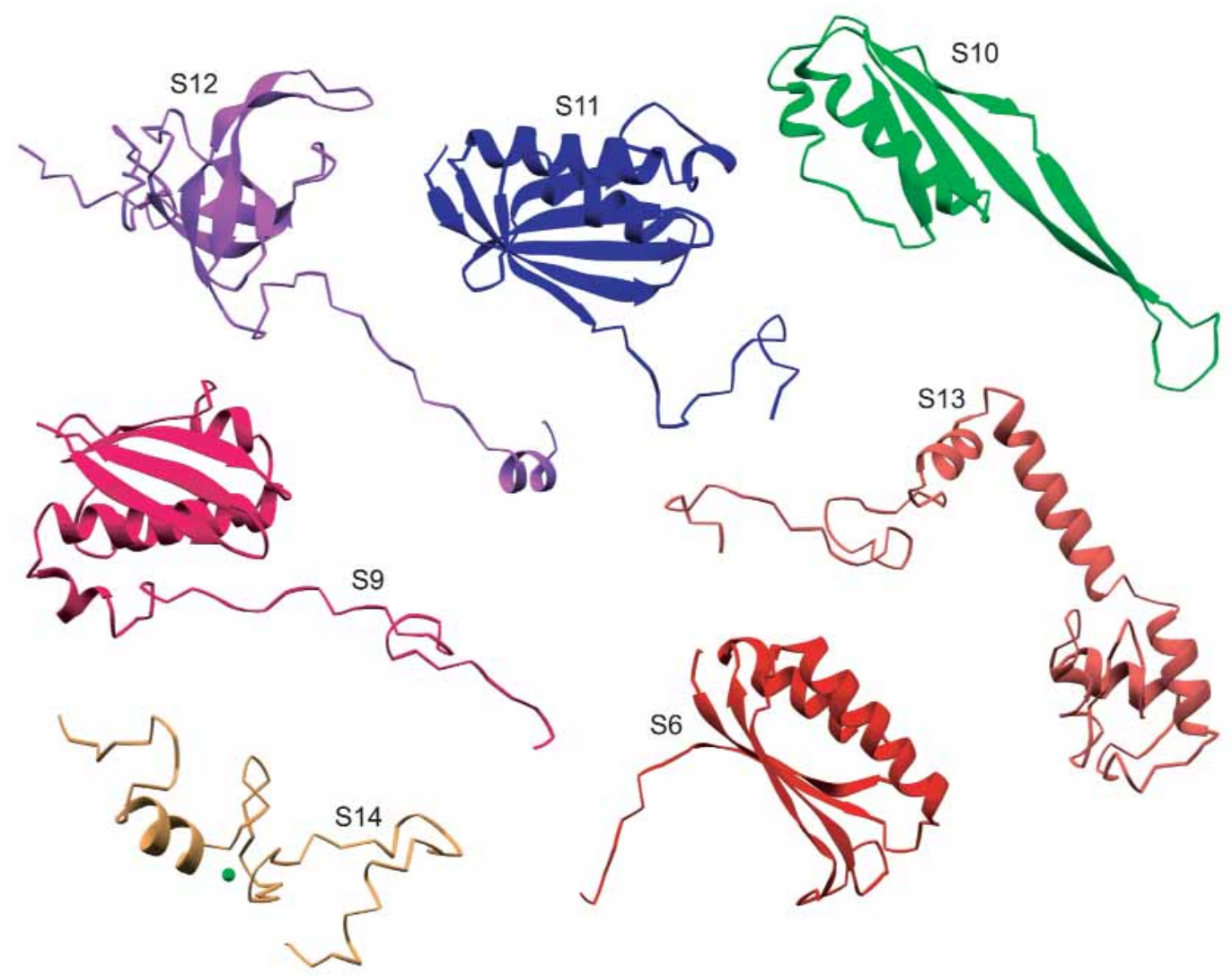

Figure 3. Protein structure gallery. Examples of structures of 30S proteins with long extensions. Of these, only the structure of S6 was determined in isolation. S14 contains a bound zinc ion which is shown as a green sphere.

Interestingly, proteins characterized as primary binders in the $30 \mathrm{~S}$ assembly map are all globular and lack the long extensions. These proteins generally bind at multihelix junctions, such as S4 at the 5-way junction of helices 3, 4, 16,17 , and 18; S7 at the junction of helices 29, 30, 41, and 42; and S15 at the junction of helices 20, 21, and 22. The primary binders are very likely to be involved in condensing 16S RNA around multihelix junctions in agreement with a great deal of prior data (Nowotny and Nierhaus 1988; Agalarov and Williamson 2000). Finally, proteins with similar or even identical folds, such as S6, S10, and S11, bind RNA in different ways, suggesting that it is difficult to make inferences about RNA binding from topology.

\section{COMPARISON WITH AN INDEPENDENT 3OS STRUCTURE}

The same month that our structure was published, an independent $3.3 \AA$ structure of the $30 \mathrm{~S}$ subunit from the Max Planck/Weizmann group was reported (Schluenzen et al. 2000). A comparison reveals a very similar overall conformation of the $30 \mathrm{~S}$ subunit in the two structures. Thus, there appears to be little evidence to support the claim that heating in the presence of tungsten clusters leads to a functionally more active form of the particle (Tocilj et al. 1999; Schluenzen et al. 2000). Although the global path of the RNA backbone is in agreement with ours, there are many significant differences in the details. In the Max Planck/Weizmann structure, regions of RNA such as the 560 and 967 loops are missing, irregular conformations of RNA are often modeled differently, and the RNA registry differs from ours in several regions, with these regional differences accounting for about 300 out of 1500 nucleotides. The root mean square deviation (rmsd) between equivalent phosphorus atoms in these regions of discrepancy is $6.1 \AA$ compared to $3.6 \AA$ for the whole RNA. In the Max Planck/Weizmann structure, the previously unsolved proteins are modeled as $\mathrm{C} \alpha$ traces with unidentified residues and are often noncontiguous and incomplete. Major differences in proteins fall into the categories of missing domains (e.g., S2, S4), missing extensions or loops (e.g., S7, S9, S13), or incompatible topologies (e.g., S11, S12, S17). Part of their S3 corresponds to our S14, and S20 has completely reversed polypeptide chain direction. We attribute most of these discrepancies to differences in interpretation of the electron density rather than genuine differences in conformation. Support for this view comes from the observation that recent structures of the $30 \mathrm{~S}$ subunit published by the Max Planck/Weizmann group are in very close agreement with the structure we originally published about 8 months earlier, with an rmsd between phosphorus atoms of about $1 \AA$ (Pioletti et al. 2001). Any differences that 
remain could be the result of slightly different crystallization conditions as well as the fact that tungsten clusters are part of the Max Planck/Weizmann structure, but not of ours.

\section{BINDING SITES FOR tRNA AND mRNA}

A precise analysis of the tRNA- and mRNA-binding sites was made easier by the occurrence of two fortuitous interactions. The spur (helix 6) from a neighboring molecule in the crystal is inserted into the $\mathrm{P}$ site of the 30S subunit and mimics P-site tRNA (Carter et al. 2000). Interestingly, the $3^{\prime}$ end of 16S RNA is folded back into the mRNA-binding cleft, and nucleotides are visible in both the P- and the E-site codons. The terminal three bases of this "pseudo-message" form noncanonical base pairs with the "anticodon" from the spur. Thus, the form of the $30 \mathrm{~S}$ we crystallized appears to have mimics for tRNA in the P site and mRNA in the P and E sites. In hindsight, it is clear why this crystal form diffracts well even in the absence of bound ligands: It effectively mimics a ligand-bound form through crystal contacts. It is also interesting that in the absence of added mRNA, the $3^{\prime}$ end of 16S RNA is folded back into the $30 \mathrm{~S}$ cleft in crystals of $70 \mathrm{~S}$ ribosomes also (see Noller et al., this volume). This suggests that the binding of the $3^{\prime}$ end of 16S RNA into its own mRNA-binding cleft in the $30 \mathrm{~S}$ subunit is not just a crystal-packing artifact. Rather, the intramolecular burial of the $3^{\prime}$ end of 16S RNA into the message-binding cleft may be energetically more favorable than bind- ing mRNA for entropic reasons, except when extensive additional compensating interactions are made with mRNA; e.g., in base-pairing of the $3^{\prime}$ end with the ShineDalgarno sequence. This feature may therefore have the benefit of making initiation more specific.

The $7.8 \AA$ structure of the $70 \mathrm{~S}$ with mRNA and tRNA identified two elements of the 30S subunit, helix 27 and helix 44 (Cate et al. 1999). Using these two elements, we were able to superimpose the $70 \mathrm{~S}$ structure onto our atomic model for the $30 \mathrm{~S}$ subunit to arrive at a model for the interaction of tRNA with the $30 \mathrm{~S}$ subunit (Fig. 4a). The superposition provided additional evidence that the spur and 3' end of 16S RNA were good mimics of P-site tRNA and mRNA, respectively, as discussed above. In addition, it allowed us to deduce details of the interactions of tRNA and mRNA with the 30S subunit (Carter et al. 2000). As an example, details of the interaction of the P-site tRNA mimic and codon with the $30 \mathrm{~S}$ subunit are shown in Figure $4 b$.

As had been revealed by previous biochemical data, the P-site tRNA makes extensive interactions with the 30S subunit. On the other hand, the A site is shallow and wide, which is consistent with both its lower affinity for tRNA and the need to allow tRNA to rotate significantly from its initial conformation as part of the ternary complex with EF-Tu (Stark et al. 1997) to its eventual conformation after GTP hydrolysis and accommodation, in which the acceptor arm of tRNA swings into the peptidyl transferase site. Additionally, the structure shows that helix 44, helix 34, protein S12, and the 530 loop are all part

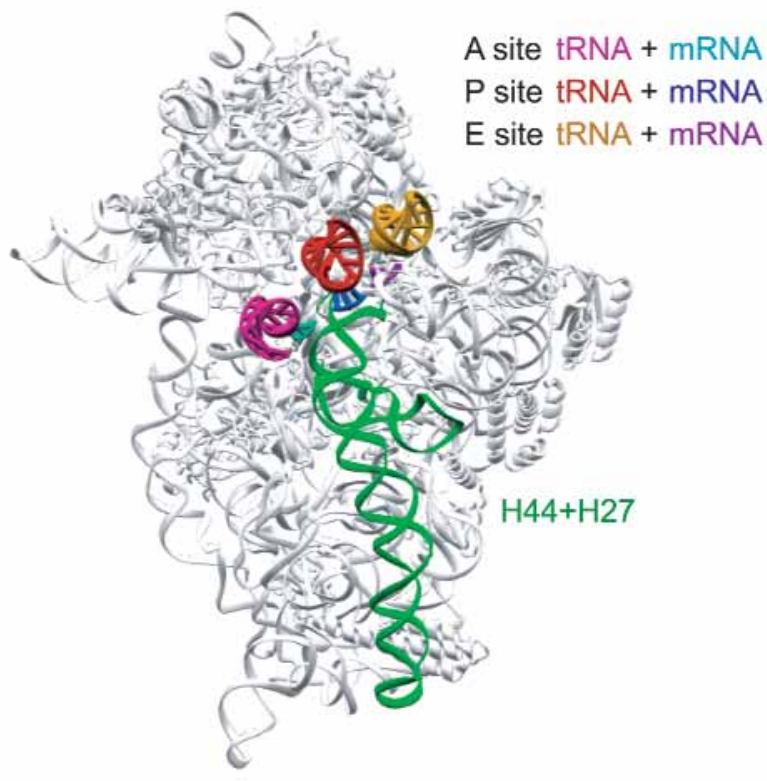

a

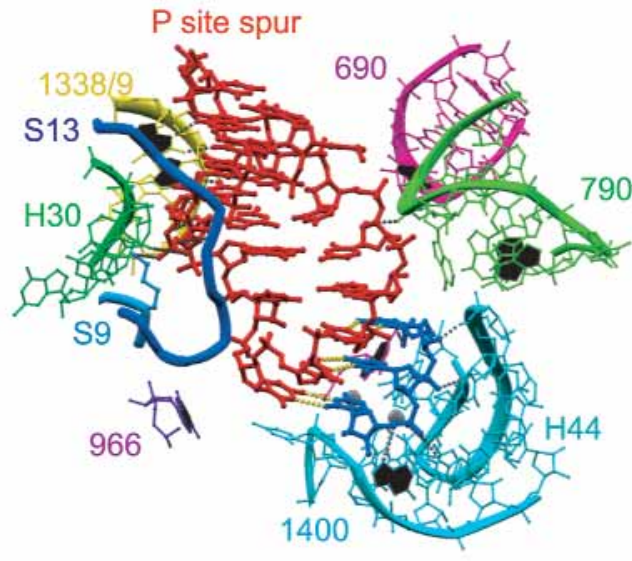

b

Figure 4. tRNA-binding sites of the small subunit. (a) Overview of the three tRNA molecules modeled onto the $30 \mathrm{~S}$ structure using the $7.8 \AA$ structure of $70 \mathrm{~S}$ in complex with tRNA and mRNA. The two $16 \mathrm{~S}$ elements used for the superposition (helices 44 and 27 ) are shown in green. (b) Details of the interactions in the P site made by the spur (helix 6 ) from a neighboring subunit in the crystal that mimics tRNA. The $3^{\prime}$ end of 16S RNA is folded into the cleft of the $30 \mathrm{~S}$ and mimics mRNA (dark blue). The spur is shown in red, and the elements of 16S RNA and ribosomal proteins are labeled and colored independently for clarity. Dotted yellow lines indicate base-pairing between the spur and the codon mimic (dark blue), and dotted black lines indicate hydrogen bonds. Bases with black filling have previously been implicated in P-site tRNA or mRNA binding. (Reprinted, with permission, from Carter et al. 2000 [copyright Nature] http://www.nature.com.) 
of the A site where decoding occurs. This confirms the suggestion by Brimacombe and coworkers based on cross-linking experiments with mRNA that these elements are close to the decoding site (Dontsova et al. 1992).

The tRNA-binding sites have several striking features that were previously either unsuspected or only hinted at. Whereas the A and P sites consist mainly of RNA elements, the E-site tRNA includes extensive interactions with proteins S7 and S11. A second unexpected finding was that long tendrils of extended polypeptide chains from S9 and S13 make their way into the tRNA-binding sites. In particular, the lengths of the S9 tail and its terminal lysine residue are highly conserved, suggesting that it makes a crucial interaction with tRNA.

The tRNA interactions deduced from the $30 \mathrm{~S}$ structure are consistent with a large body of biochemical data and have subsequently been confirmed by the $5.5 \AA$ resolution structure of the 70S ribosome with mRNA and tRNA (Yusupov et al. 2001), as well as our complex of mRNA and an anticodon stem-loop of tRNA with the 30S subunit (Ogle et al. 2001).

\section{ROLE OF THE 30S SUBUNIT IN DECODING}

A central role of the $30 \mathrm{~S}$ is decoding, or selection of the correct aminoacylated tRNA for participation in peptidyl transferase. The discrimination inherent in codon-anticodon base-pairing leads to a free-energy difference of only $2-3 \mathrm{kcal} / \mathrm{mole}$ between cognate tRNA and near-cognate tRNA (which has a single mismatch). This difference would predict an error rate of about $10^{-2}$, which is 1-2 orders of magnitude higher than the observed error rate of translation (Kurland 1992).

Ever since the discovery that antibiotics can increase the error rate of translation, it has been proposed that the ribosome can modulate the fidelity of translation by directly monitoring codon-anticodon base-pairing (Davies et al. 1964). The site where this monitoring occurs is referred to as the decoding site, and by definition, it must be part of the environment of A-site tRNA. Two possible mechanisms have been proposed to account for the improved accuracy. The first involves recognition by the ribosome of the geometry of correct codon-anticodon base-pairing in the same way that enzymes recognize the geometry of the correct substrate and discriminate against incorrect ones (Eigen and De Maeyer 1966; Potapov 1982; Thompson and Dix 1982). In an alternative mechanism, selection of the correct tRNA would be based on a kinetic proofreading scheme, in which the energy discrimination inherent in codon-anticodon pairing is used twice, by having an initial selection and a "proofreading" step that are separated by an irreversible step (Hopfield 1974; Ninio 1975). In the case of the ribosome, the irreversible step would be the hydrolysis of GTP by EF-Tu. Thus, an error rate of $10^{-2}$ at each step could result in a total error rate as low as $10^{-4}$ if each step was allowed to reach equilibrium. Because of the need for speed, the overall accuracy is reduced from the maximum possible, but it is still sufficient to account for the error rate of pro- tein synthesis. Therefore, in the context of proofreading schemes, it is not clear that recognition of codon-anticodon pairing geometry by the ribosome is even necessary. However, when a slowly hydrolyzable GTP analog was used, it was shown that even a single selection step could theoretically have a discrimination sufficient to account for the accuracy of protein synthesis, provided equilibrium could be reached, which gave evidence for the ability of the ribosome to recognize the geometry of codon-anticodon base-pairing (Thompson and Karim 1982).

\section{LOCATION OF THE DECODING SITE}

Where is the decoding site in the $30 \mathrm{~S}$ subunit? Data from footprinting (Moazed and Noller 1990), cross-linking (Dontsova et al. 1992), and genetics (O'Connor et al. $1995,1997)$ have implicated the region that includes helix 44, the 530 loop, and helix 34 in the ribosomal A site. These regions are all close together in the structure. More recent work on decoding has focused on two universally conserved residues, A1492 and A1493, which are part of an internal loop in helix 44. These residues are essential for both viability and A-site tRNA binding (Yoshizawa et al. 1999). This internal loop is also the binding site for the antibiotic paromomycin and related aminoglycosides, which increase the error rate of protein synthesis. In a nuclear magnetic resonance (NMR) structure of paromomycin bound to a fragment of helix 44, it was shown that the drug displaces A1492 and A1493 toward the minor groove of helix 44 (Fourmy et al. 1996). On the basis of biochemical experiments, it was concluded that the N1 of the two bases directly interacted with the $2^{\prime} \mathrm{OH}$ of mRNA (Yoshizawa et al. 1999), and that the bases were involved in recognition of the shape of the codon-anticodon helix via minor-groove interactions. However, the same data could be used to arrive at a completely different model that involved interaction of the codon-anticodon helix with the major groove of helix 44 (VanLoock et al. 1999). In any case, when the $7.8 \AA$ structure of the $70 \mathrm{~S}$ ribosome with tRNA was determined, modeling the NMR structure of the internal loop with or without paromomycin into the 70S electron density suggested that the adenines were too far away from the codon-anticodon helix to have a direct role in decoding (Cate et al. 1999).

These discrepancies began to be resolved when the structure of the $30 \mathrm{~S}$ subunit complexed with spectinomycin, streptomycin, and paromomycin showed that rather than displace them into the minor groove in a way that would preserve the A1493-A1408 base pair reported in the NMR structure (Fourmy et al. 1996), paromomycin in fact flipped A1492 and A1493 completely out of the internal loop of the helix so that they pointed into the A site (Carter et al. 2000). Modeling of A-site tRNA and mRNA showed that these bases would be in a position to bind directly in the minor groove of the codon-anticodon helix. However, they would do so in a way that would place the $\mathrm{N} 1$ of the adenines pointing toward tRNA rather than interacting with the $2^{\prime} \mathrm{OH}$ of mRNA, as had previously been proposed (Yoshizawa et al. 1999). There are 
several examples of highly conserved adenines in $16 \mathrm{~S}$ RNA that form tertiary interactions with the minor groove of A-form helices. These interactions involve hydrogen bonding of the adenines with the $2^{\prime} \mathrm{OH}$ of both strands of the minor groove in a manner that would be sensitive to the shape and width of the groove. On the basis of this analysis, it was proposed that the binding of cognate tRNA would induce a similar conformational change in A1492 and A1493 to the one induced by paromomycin. The energetic cost of the conformational change would be paid for by compensating interactions between the adenines and the codon-anticodon helix. In the case of near-cognate tRNA, the fit would not be perfect, so that the induced changes would not be energetically favorable. However, paromomycin, by partially paying the energetic cost of the induced changes, would promote the binding of near-cognate tRNA and thus lead to an increased error rate.

\section{RECOGNITION OF CODON-ANTICODON BASE-PAIRING BY THE RIBOSOME}

The interactions by which the ribosome senses codon-anticodon pairing at the A site were determined experimentally by directly soaking mRNA in the form of a uridine hexanucleotide, as well as the anticodon stemloop of its cognate phenylalanyl-tRNA, into crystals of the $30 \mathrm{~S}$ subunit (Ogle et al. 2001). This work directly revealed the codon and anticodon stem-loop in the A site. In doing so, it showed that our earlier modeling of the Asite tRNA was reasonably accurate, and also that a sharp kink exists in the mRNA between the A- and P-site codons, as could be expected if each were to be part of an A-form helix with its corresponding anticodon.

The binding of cognate tRNA induces global domain movements in the $30 \mathrm{~S}$ subunit. It also causes local changes around the decoding site. In the absence of tRNA or paromomycin, A1492 and A1493 are stacked inside helix 44, and G530 is in the syn conformation (Fig. 5a). The binding of paromomycin causes A1492 and A1493 to flip out of the internal loop of helix 44, while leaving G530 in the syn conformation (Fig. 5b). On tRNA binding, A1492 and A1493 flip out of helix 44 as we had predicted, but also cause G530 on the other side of the codon-anticodon helix to switch from a syn to an anti conformation (Fig. 5c). A comparison of Figures $5 \mathrm{~b}$ and $5 \mathrm{c}$ shows that, apart from having no effect on G530, paromomycin alone does not induce precisely the same conformational changes in A1492 and A1493. This suggests that the antibiotic facilitates incorporation of near-cognate tRNA by contributing in part toward the energetic cost of changes required for recognition, rather than by creating a fully preformed binding site. Since the adenines are largely disordered in the native structure as judged by a very high B factor, but well ordered in the complexes with paromomycin or tRNA, there must be some additional entropic cost in the changes induced by binding.

A1493 makes intimate contacts with the first base pair of the codon-anticodon helix (Fig. 6a), whereas A1492 and G530 together span the minor groove of the second base pair and interact with each other via their N1 positions (Fig. 6c). The third base pair is not as closely monitored, with only the codon nucleotide making interactions with the ribosome (Fig. 6d). This is consistent with the requirement of the genetic code that the third position be able to accommodate noncanonical base pairs such as a GU wobble (Crick 1966; Yokoyama and Nishimura 1995). Moreover, the observation that the ribosome makes extensive interactions with the codon base but not the anticodon base is consistent with previous analysis suggesting that the codon base conformation is more restricted than that of the anticodon (Yokoyama and Nishimura 1995). These experiments show how the ribosome recognizes the geometry of codon-anticodon basepairing, consistent with the looser requirement at the
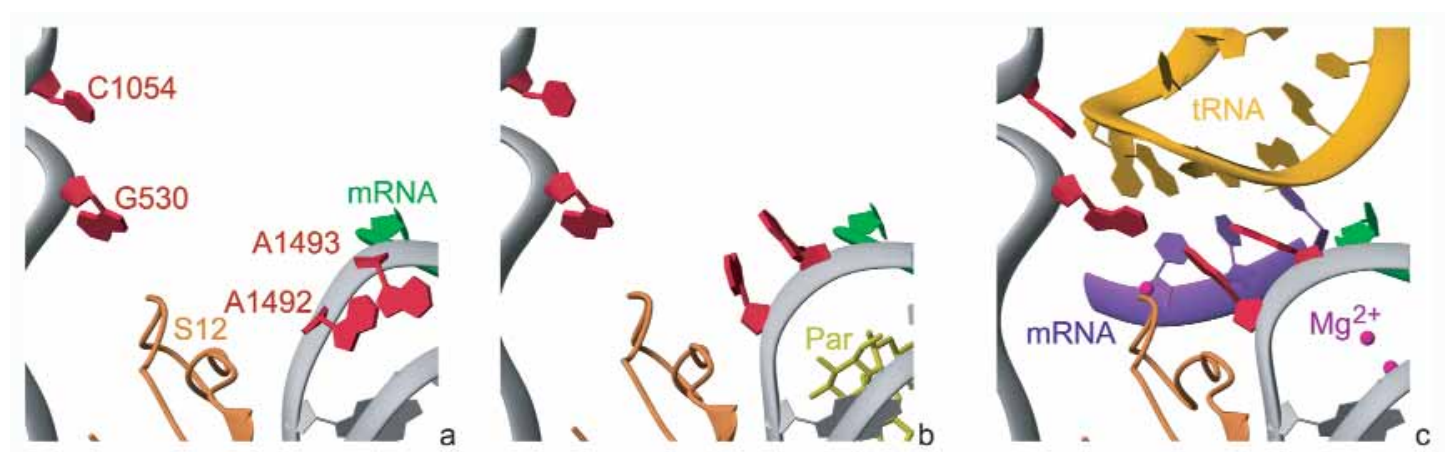

Figure 5. Overview of A-site tRNA binding. Discrete states of the 30S A site deduced from three different crystal structures of $(a)$ native, unbound $30 \mathrm{~S},(b)$ the $30 \mathrm{~S}$ in complex with paromomycin, and $(c)$ the $30 \mathrm{~S}$ in complex with mRNA and cognate tRNA. In all panels, tRNA ASL is gold, A-site mRNA codon purple, P-site mRNA codon green, protein S12 brown, and important bases involved in conformational changes red. Magnesium ions are shown as magenta spheres. (a) The A site of the native 30S subunit (Wimberly et al. 2000). A1492/3 (red, right) are stacked in the center of helix 44, and G530 is in its syn conformation. C1054 is shown in the upper left corner. (b) In the paromomycin-bound 30S (Carter et al. 2000), the bases of A1492 and A1493 have been pushed out into the A site by the antibiotic binding to the center of helix 44 (yellow sticks, lower right). (c) In the 30S:ASL:U6 complex, A1492/3 flip out to monitor the codon-anticodon interaction and G530 has switched to its anti conformation to stabilize the interaction of the second position. Two Mg ions are visible in the place where A1492/3 are located in the native structure. (Reprinted, with permission, from Ogle et al. 2001 [copyright AAAS] http://sciencemag.org.) 

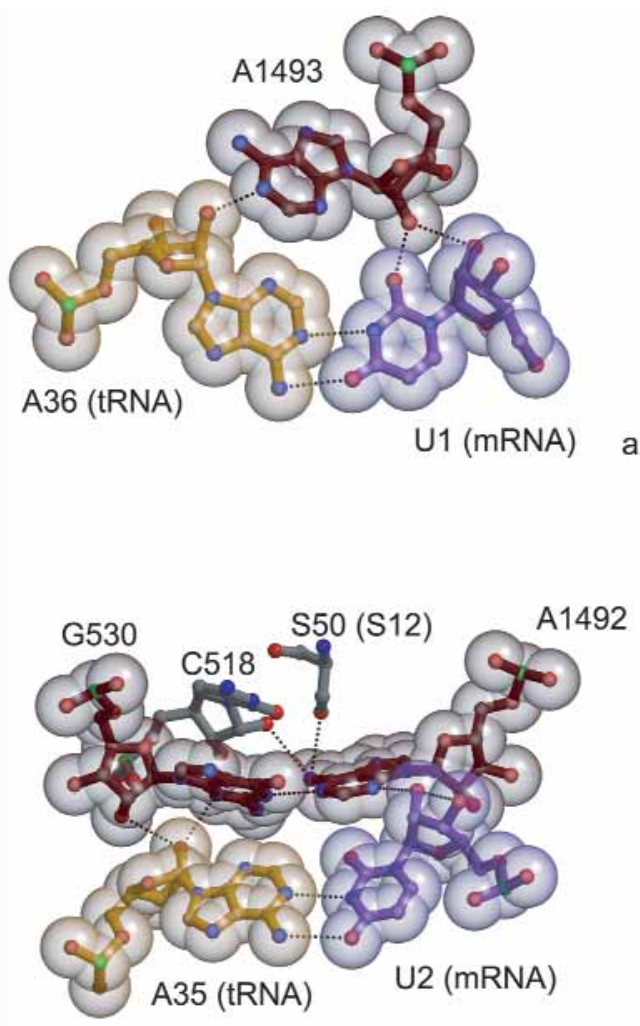
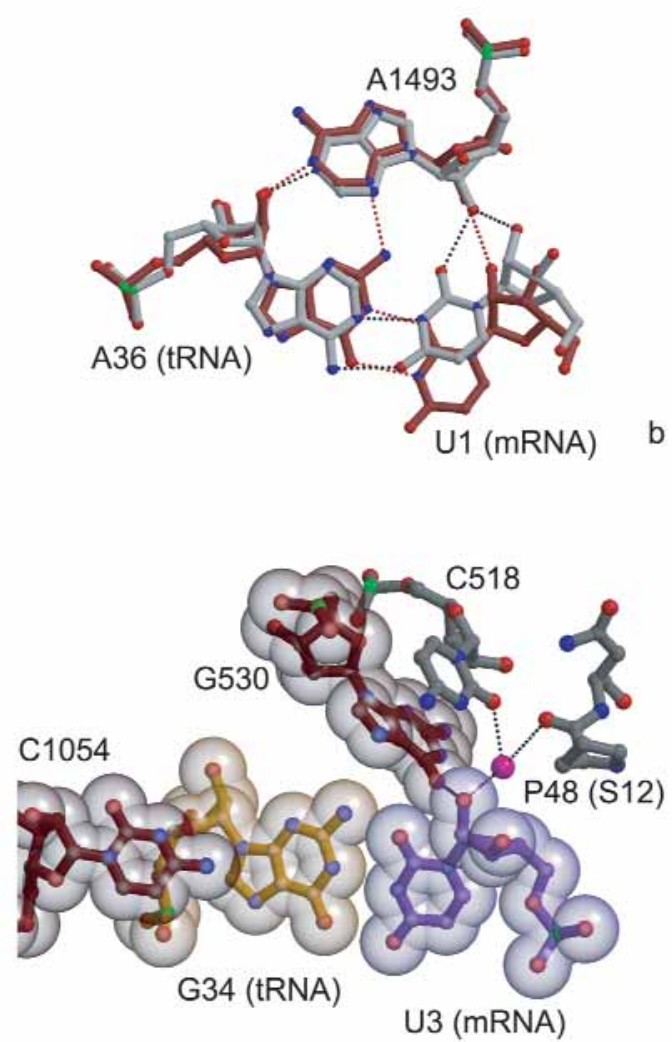

Figure 6. Details of the interactions at the A site. Interactions at the first, second, and wobble positions of the codon-anticodon minihelix. In panels $a, c$, and $d$, the codon (U6) is shown with purple sticks, the anticodon (ASL) with gold sticks, and the monitoring bases with brown sticks. (a) At the first position, the minor groove of the A36:U1 base pair is monitored by A1493 (brown). (b) A superposition of the base pairs in the first position with cognate (gray) and near-cognate (brown) tRNA. (c) At the second position, G530 and A1492 (both brown) act in concert to monitor the base pair A35:U2. (d) The Watson-Crick-like base-pairing in the wobble position of the 30S:ASL:U6 complex with C1054 (brown) stacking against the ribose of A35. The codon-anticodon interaction at the wobble position is stabilized by a Mg-mediated interaction with C518 and residues P48 and N49 from protein S12 (gray sticks). (Panels $a, c$, and $d$ reprinted, with permission, from Ogle et al. 2001 [copyright AAAS] http://sciencemag.org.)

wobble position. The structure explains previous chemical modification data and also rationalizes the requirements for adenines at 1492 and 1493 and a guanine at 530. Only purines would be able to span a minor groove, but a guanine at 1492 or 1493 could not have the same conformation as either adenine because of a steric clash with the minor groove from its $\mathrm{NH} 2$ at the N2 position. Guanines also would not be able to make the analogous hydrogen bonds through their N1 positions. Similarly, only guanine at G530 would be able to form the observed bond with A1492 through the N1 position. Finally, because DNA has no 2' OH group and, also, DNA-RNA hybrids have a different groove width and shape, the structure explains the classic observation that DNA is a poor template for translation but is less so in the presence of the aminoglycoside neomycin (McCarthy and Holland 1965). It also explains the inability of the ribosome to bind tRNA in the A site when the codon consists of DNA rather than RNA (Potapov et al. 1995).

Recently, we have also determined the structure of the anticodon stem-loop of near-cognate tRNA in complex with the $30 \mathrm{~S}$ subunit. This near-cognate tRNA, which codes for leucine, has a GAG anticodon, and hence has a
GU wobble in both the first and third positions using the poly-U mRNA. In the absence of paromomycin, no density is visible for tRNA in the A site, whereas weak density is visible for mRNA. In the presence of paromomycin, the structure is very similar to that of cognate tRNA. However, because the first base pair of the codon-anticodon helix is a GU wobble pair rather than a Watson-Crick base pair, the fit of A1493 with the minor groove of this base pair is distorted and hence energetically less favorable. Interestingly, in comparison with the cognate case, it is the codon base rather than the anticodon that has moved to accommodate the wobble pair at the first position (Fig. 6b).

These experiments show that the ribosome recognizes cognate tRNA through an induced-fit mechanism that monitors the geometry of the minor groove of codon-anticodon base-pairing. In doing so, the ribosome uses principles found in other systems. The interactions of A1493 and A1492 with the minor groove are identical to those classified as type I and type II A minor interactions (Nissen et al. 2001), which are found in tertiary interactions in the group I intron, and both 23S RNA and 16S RNA. Much of the free energy of the interaction ap- 
pears to arise from the shape complementarity of the adenines to the minor groove (Doherty et al. 2001). The principles of minor groove recognition by surface complementarity and sequence-independent hydrogen bonding to ensure fidelity of base-pairing are also employed by DNA and RNA polymerases (Doublie et al. 1998; Kiefer et al. 1998; Cheetham and Steitz 1999).

Since our experiments involve just the anticodon stemloop of tRNA in the context of the $30 \mathrm{~S}$ subunit, a natural question concerns what state these structures represent along the reaction pathway. The conformation of the anticodon stem-loop is virtually identical to that of the Asite tRNA in the 70S structure (Yusupov et al. 2001), suggesting that it represents a post-accommodation state of tRNA. Our structure therefore has no direct bearing on the initial recognition step in which a ternary complex of EF-Tu with tRNA and GTP binds to the ribosome. However, we note that the protections observed on the binding of the ternary complex of EF-Tu with tRNA to the ribosome are essentially the same as those observed on nonenzymatic tRNA binding (Powers and Noller 1994), and both are consistent with our structure. This suggests that despite a large change in the orientation of the tRNA, many of the interactions of the ribosome with the codon-anticodon helix observed here probably occur in the initial recognition step and persist through GTP hydrolysis to accommodation. It is clear that A1492 and A1493 are in a conformationally variable region of the 30S subunit and possibly can rotate with the tRNA after the initial binding. This hypothesis needs to be tested experimentally by determining a high-resolution structure of the ternary complex with the ribosome.

\section{PROOFREADING}

The basis of proofreading is that the initial binding of tRNA occurs as part of its ternary complex with EF-Tu, and the complex can dissociate at this step. Following GTP hydrolysis by EF-Tu, the aminoacylated end of the tRNA is free to move into the peptidyl transferase site in the accommodation step. During this process, which is part of the proofreading step, tRNA has a second chance to dissociate. The broad consensus is that proofreading is an important step in ensuring the accuracy of protein synthesis (Thompson and Stone 1977; Ruusala et al. 1982; Rodnina and Wintermeyer 2001). However, this view is not unanimous, and Nierhaus and coworkers have proposed an alternative model that excludes proofreading (Nierhaus 1990). Although recognition of the geometry of codon-anticodon base-pairing is an essential ingredient of this alternative model, we note that our demonstration that such recognition occurs does not preclude a proofreading step.

There are several lines of evidence for a proofreading step, the most important of which is that the number of molecules of GTP hydrolyzed per amino acid incorporated is much higher for near-cognate tRNA than for cognate tRNA, showing that near-cognate tRNA can trigger GTP hydrolysis but is usually rejected subsequently and only occasionally incorporated (Thompson and Stone 1977; Ruusala et al. 1982). In addition, it is known that mutations in the ribosome not directly at the decoding site, e.g., in the tRNA but distant from the anticodon loop (Hirsh 1971), 23S RNA (O'Connor and Dahlberg 1993; Bilgin and Ehrenberg 1994), or EF-Tu (Tapio and Isaksson 1988), can affect accuracy. This argues that considerations other than geometric recognition of codon-anticodon base-pairing, such as the kinetics of various steps in the proofreading hypothesis, also play an essential role in the accuracy of translation.

An important insight into how the ribosome carries out proofreading comes from studies of the antibiotic streptomycin, which is known to reduce the accuracy of protein synthesis (Davies et al. 1964), by affecting primarily the proofreading step (Ruusala and Kurland 1984). Mutants resistant to streptomycin are generally hyperaccurate, whereas ribosome ambiguity (ram) mutants, often found as suppressors of streptomycin dependence, are more error-prone than wild-type ribosomes. Moreover, the effects of streptomycin binding and ram mutations are not additive, suggesting that their effects arise from a similar mechanism (Ruusala and Kurland 1984).

Restrictive mutations are usually found in protein $\mathrm{S} 12$, whereas ram mutants usually occur on proteins S4 and S5. However, recently both ram and restrictive phenotypes have been generated by mutations in helix 27 of 16S RNA (Lodmell and Dahlberg 1997). Chemical probing studies show that ram and restrictive ribosomes have altered chemical reactivity in portions of helices 27 and 44 of 16S RNA (Allen and Noller 1989). More recent chemical probing (Lodmell and Dahlberg 1997) and cryo-electron microscopy (Gabashvili et al. 1999) provide evidence that the ram and restrictive ribosomes may have altered conformations throughout the 30S subunit.

A model has been proposed in which the ribosome switches between ram and restrictive states even during normal translation (Lodmell and Dahlberg 1997). After hydrolysis of GTP by EF-Tu, the ribosome enters a restrictive conformation that favors dissociation of tRNAs. This is followed by a transition to another state in which the tRNA is stably bound and can become available for peptide-bond formation. Near-cognate tRNAs are more likely to dissociate from the restrictive conformation, whereas cognate tRNAs are more likely to progress to peptide-bond formation. Restrictive mutations alter the energetics of the ribosome so that the lifetime of the restrictive state is prolonged, and hence incorrect tRNAs are more likely to be rejected. In contrast, ram mutations "destabilize" this restrictive state, so that more tRNAs (even near-cognate ones) are likely to stay bound to the ribosome.

The structure of the $30 \mathrm{~S}$ subunit shows the locations of the streptomycin-binding site as well as mutations that affect translational accuracy. The environment of helix 27 in the 30S crystal structure is shown in Figure 7a. The bases with altered chemical reactivity in the ram and restrictive states (Allen and Noller 1989) lie at the interface between helix 27 and helix 44. In our structure, bases 888-890 of helix 27 are present in the S-turn conformation thought to be characteristic of the ram state (Lodmell and Dahlberg 1997). As shown in Figure 7b, the ram mutations that occur in S4 and S5 lie mainly at the interface between the two proteins (Clemons et al. 1999; Wimberly 

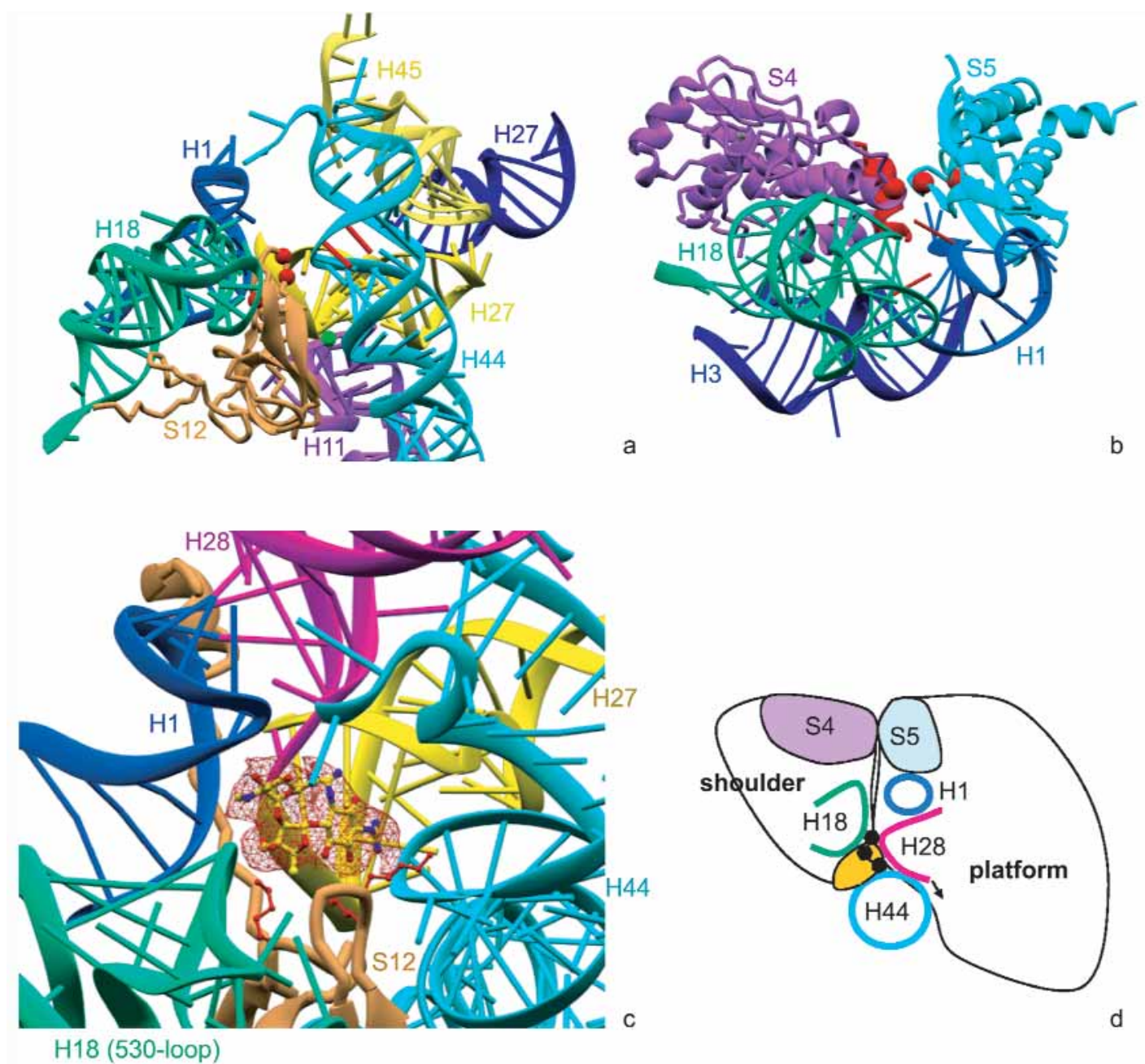

Figure 7. The effect of streptomycin. (a) The environment of helix 27 (yellow) in the 30S subunit. Red balls highlight sites of restrictive mutations in S12, red sticks show A1492 and A1493. (b) The helix 1-helix 18 interaction surface is contiguous with the S4S5 surface. The locations of ram mutations in S4 and S5 are highlighted in red, as are the locations of residues 8 and 26 in S4 whose chemical reactivity changes in ram mutants. (c) The streptomycin-binding site, showing the interactions with helix 27, the 530-loop (helix 18), helix 44, and ribosomal protein S12. Streptomycin is shown in a stick representation along with the difference Fourier density $(\mathrm{red})$. (d) Schematic horizontal cross-section of the 30S in the streptomycin-binding region showing the approximate location of the elements involved in controlling the $\mathrm{ram} /$ restrictive equilibrium. S12 is shown in yellow. (Panels $a-c$ reprinted, with permission, from Carter et al. 2000 [copyright Nature] http://www.nature.com.)

et al. 2000). This interface is contiguous with an RNA-RNA interface between helix 1 and the 530 loop (helix 18). Together, they represent a hybrid protein-RNA interface that could be disrupted during conformational changes in the $30 \mathrm{~S}$ subunit. Streptomycin binds tightly in a pocket where it interacts with the phosphate backbone from four regions of 16S RNA (helices 1, $18,27 / 28$, and 44) as well as the highly conserved Lys-45 (E. coli Lys-42) of S12 (Fig. 7c) (Carter et al. 2000). All of these regions lie at the interface between the shoulder and platform domains of the 30S subunit (Fig. 7d).

Together, these observations implicate movement at this interface in the conformational changes associated with proofreading. At one end of the interface, mutations in S4 and S5 that disrupt their interaction lead to the ram phenotype, probably by destabilizing the restrictive state and thus accelerating the transition to a ram state. In contrast, mutations in S12 that disrupt interactions at the other end of the interface probably prolong the lifetime of the restrictive state, whereas streptomycin, which stabilizes interactions in the $\mathrm{S} 12$ region, suppresses the effect of these mutations (Kurland et al. 1996). In the extreme case of streptomycin-dependence mutations in S12, the transition to the ram state is so unfavorable that streptomycin is actually required for function. Interestingly, the single known mutation in S12 that leads to streptomycin resistance without a hyperaccurate phenotype is K45R (E. coli $\mathrm{K} 42$ ). This lysine makes direct hydrogen bonds with two $\mathrm{OH}$ groups on streptomycin as well as a salt bridge to A913. Its mutation to an arginine would have the effect of disrupting streptomycin binding but would not disrupt its interactions with the ribosome, since the arginine could make the same salt bridge to A913.

Without knowing the structure of the restrictive and ram states, it is difficult to predict how streptomycin and accuracy mutations would affect the transition between 
them. Moreover, it remains unclear how the changes in conformation observed in the mutants relate to conformational changes in the ribosome during the elongation cycle. In addition to structural work, the ram and restrictive states need to be placed rigorously in a kinetic pathway from initial selection to peptidyl transferase. Although the details of proofreading remain to be elucidated, the movement between the platform and shoulder domains of the $30 \mathrm{~S}$ subunit that has been observed recently on cognate tRNA binding or IF1 binding (Carter et al. 2001; Ogle et al. 2001) supports the proposal that movement between these domains is involved.

\section{COMPLEXES WITH ANTIBIOTICS}

Many antibiotics act by binding to the large or small ribosomal subunit, and an enormous amount of work has gone into elucidating the biochemical basis for their action (Spahn and Prescott 1996). Most antibiotics appear to bind to the RNA component of the ribosome, although many resistance mutations map to ribosomal proteins.

Despite decades of biochemical work, it has not been possible until recently to obtain direct structural information on the binding of antibiotics to ribosomes because of the lack of a high-resolution structure of either subunit. A notable exception was the site in helix 44 that contains an internal loop implicated in decoding. This region was shown to bind antibiotics as an isolated fragment (Purohit and Stern 1994) and was used to determine the structures of paromomycin and gentamicin in complex with RNA (Fourmy et al. 1996; Yoshizawa et al. 1998).

With the determination of atomic structures for ribosomal subunits, the situation has changed dramatically. It is now possible to determine the structures of complexes of antibiotics with either ribosomal subunit by cocrystallization or by soaking the native crystals in antibiotic. Refinement of the coordinates of the native structure against diffraction data from the antibiotic complex directly reveals density corresponding to the antibiotic molecules in difference Fourier maps. Using this approach, we have determined the structure of the $30 \mathrm{~S}$ subunit in complex simultaneously with streptomycin, spectinomycin, and paromomycin (Carter et al. 2000) and also separately with tetracycline, hygromycin $\mathrm{B}$, and pactamycin (Brodersen et al. 2000). The locations of these antibiotics in the $30 \mathrm{~S}$ structure are shown in Figure 8. These structures shed light on the mechanism of action of the antibiotics, as discussed above for paromomycin and streptomycin in the context of decoding and proofreading. We briefly mention below the results for the other antibiotics.

\section{Tetracycline}

Tetracycline is known to have a single strong binding site in the entire ribosome, located in the $30 \mathrm{~S}$ subunit, in addition to several weaker binding sites on both subunits (Epe et al. 1987; Kolesnikov et al. 1996), but only the strong binding site is responsible for its inhibitory action during translation (Buck and Cooperman 1990). We observe two tetracycline sites in the $30 \mathrm{~S}$ subunit. The strong or primary binding site makes contacts with an irregular minor groove of helix 34 and peripherally with bases 964-967 in helix 31. This position places it in the A site of the $30 \mathrm{~S}$ subunit, in a position that would sterically clash with A-site tRNA after accommodation. The structure thus explains the observation that tetracycline bind-
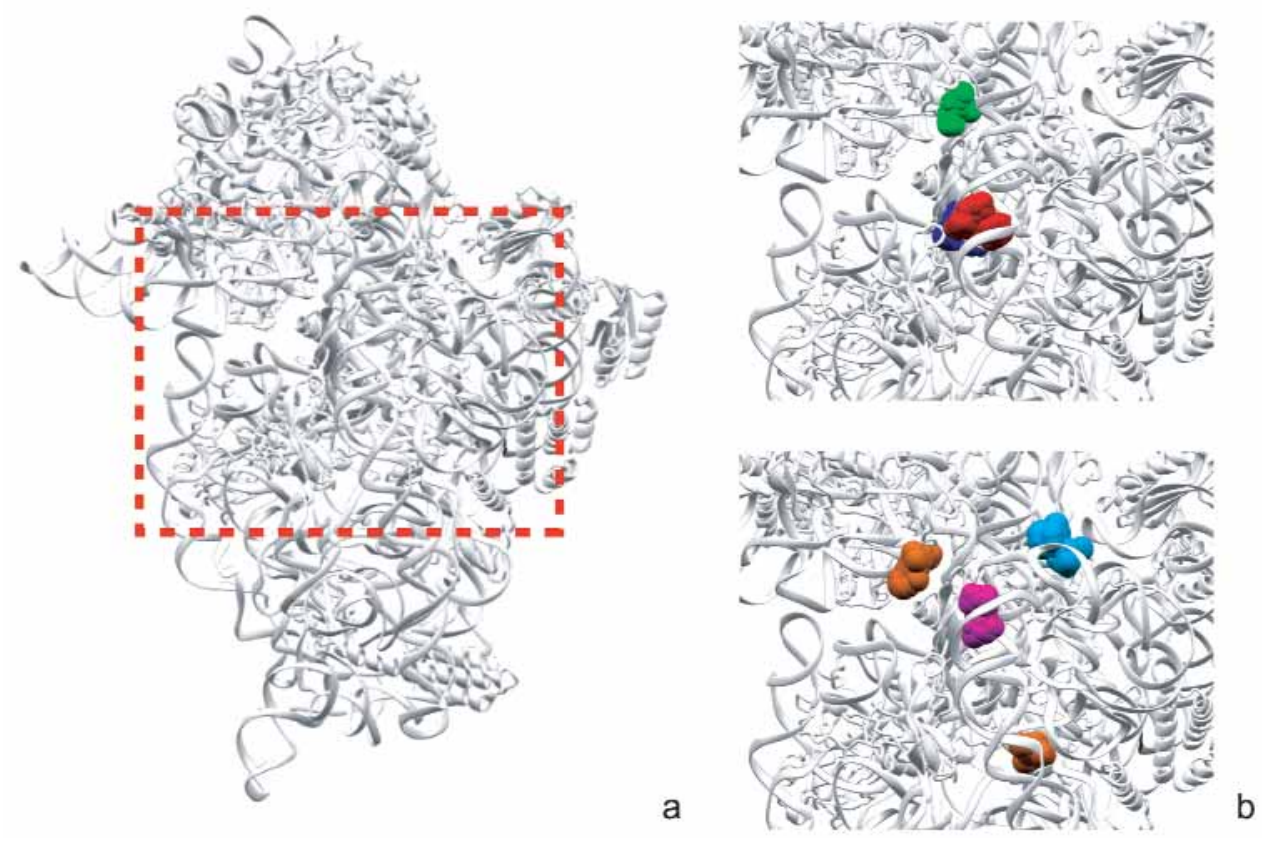

Figure 8. Antibiotics bound to the $30 \mathrm{~S}$ subunit. (a) Overview of the $30 \mathrm{~S}$ subunit outlining the central region in which the antibiotics we have studied bind. (b) The central region expanded to show the locations of streptomycin (blue), spectinomycin (green), paromomycin (red), tetracycline (orange), pactamycin (cyan), and hygromycin B (magenta). 
ing prevents the binding of A-site tRNA but allows GTP hydrolysis by EF-Tu (Gordon 1969). It is also consistent with extensive data on positions on the tetracycline molecule that cannot be modified without losing antibiotic activity (Chopra 1985). These positions are all involved in making interactions with the $30 \mathrm{~S}$ subunit, whereas the positions where modifications are allowed are not. We also see a second binding site for tetracycline between helix 27 and helix 11 that is consistent with biochemical footprinting data (Moazed and Noller 1987). It is not clear that this second site has any relevance for the action of tetracycline. However, helix 27 is known to be the site of an accuracy switch in the ribosome (as discussed above in the section on proofreading), and this site may have some synergistic effect with the primary site at helix 34.

Recently, a second structure of the complex of the $30 \mathrm{~S}$ subunit with tetracycline was published by the Max Planck/Weizmann group (Pioletti et al. 2001). This complex, at $4.5 \AA$ resolution, shows six binding sites for tetracycline. Only one of these, the primary binding site at helix 34, is common to both structures. A site observed near helix 27 is distinct from our secondary site near that location and appears not to be consistent with protection data (Moazed and Noller 1987). Other sites observed in the Max Planck/Weizmann structure are consistent with various biochemical data on affinity labeling by tetracycline analogs. However, despite a nominally higher resolution and concentration of tetracycline, we see no signs of these additional sites in our difference Fourier maps. It is not clear whether the differences arise from the data or from the actual soaking times and conditions. In any case, our current opinion is that the minor sites are not relevant physiologically, and the site observed in both structures, namely the A site, is responsible for the effect of tetracycline on protein synthesis.

\section{Pactamycin, Hygromycin B, and Spectinomycin}

Pactamycin binds to the ribosomal E site, where it displaces mRNA and could affect initiation by interfering with interaction with either the Shine-Dalgarno sequence or initiation factors (Brodersen et al. 2000). Hygromycin $\mathrm{B}$ binds to the major groove of helix 44 near the $\mathrm{P}$ site (Brodersen et al. 2000). This region of helix 44 appears to move during translocation (Frank and Agrawal 2000), and the structure provides a rationale for how hygromycin B may inhibit its flexibility and thus translocation.

Spectinomycin binds to a minor groove of helix 34 that appears to be very close to a hinge point between the head and body (Carter et al. 2000). Its binding site is consistent with biochemical and mutational data (Sigmund et al. 1984; Brink et al. 1994). By potentially inhibiting conformational changes in the head, spectinomycin could have the effect of inhibiting translocation as observed.

\section{STUDIES ON INITIATION}

During initiation, the $30 \mathrm{~S}$ subunit binds three initiation factors, IF1, IF2, and IF3, along with initiator tRNA. As a first step in understanding the structure of the initiation complex, we have determined the structure of IF1 bound to the $30 \mathrm{~S}$ subunit. The structure shows that IF1 interacts directly with A1492 and A1493 in the A site, and its binding would sterically prevent the binding of A-site tRNA. Both of these are consistent with earlier biochemical data (Moazed et al. 1995; Dahlquist and Puglisi 2000). The binding of IF1 causes a change in the conformation of helix 44 that is propagated to result in global domain movements, and since IF1 is known to affect the rate but not extent of dissociation of 30S and 50S (Godefroy-Colburn et al. 1975), it is likely that the IF1 complex with the 30 S represents a transition state that has a lowered activation energy barrier for subunit association or dissociation.

\section{CONCLUSIONS AND FUTURE PROSPECTS}

These are exciting times to be working on ribosome structure. The recent atomic structures of the $30 \mathrm{~S}$ and $50 \mathrm{~S}$, and the subsequent lower resolution but complete molecular model of the 70S with tRNA, have changed the way that ribosome biology will be studied. The structure of the $30 \mathrm{~S}$ has given us insights into tRNA and mRNA recognition, decoding, and antibiotic function, as well as interactions with initiation factor IF1. The atomic structures of both subunits have been invaluable in the molecular interpretation of the $5.5 \AA$ resolution structure of the $70 \mathrm{~S}$ ribosome. Nevertheless, a large number of important questions remain, even in the context of the bacterial ribosome, let alone its more complicated eukaryotic counterpart. These range from the sequence of events during initiation and termination to an understanding of how GTP hydrolysis by the various factors is triggered by the ribosome and how this energy is used in various steps such as proofreading or translocation. We also need to learn much more about the molecular details of the conformational changes in the ribosome during translation.

\section{ACKNOWLEDGMENTS}

This work was supported by the Medical Research Council (UK) and National Institutes of Health grant GM-44973 (to S.W. White and V.R.). D.E.B. was the recipient of a Human Frontier Science Program postdoctoral fellowship, and W.M.C. was the recipient of a National Institutes of Health predoctoral fellowship. We dedicate this to the memory of Professor Paul Sigler, who facilitated this work at a crucial juncture.

\section{REFERENCES}

Agalarov S.C. and Williamson J.R. 2000. A hierarchy of RNA subdomains in assembly of the central domain of the $30 \mathrm{~S}$ ribosomal subunit. RNA 6: 402 .

Allen P.N. and Noller H.F. 1989. Mutations in ribosomal proteins S4 and S12 influence the higher order structure of $16 \mathrm{~S}$ ribosomal RNA. J. Mol. Biol. 208: 457.

Andersson I., Knight S., Schneider G., Lindqvist Y., Lundqvist T., Brändén C.-I., and Lorimer G.H. 1989. Crystal structure of the active-site of ribulose-bisphosphate carboxylase. Nature 337: 229.

Ban N., Nissen P., Hansen J., Moore P.B., and Steitz T.A. 2000. 
The complete atomic structure of the large ribosomal subunit at $2.4 \AA$ A resolution. Science 289: 905.

Ban N., Freeborn B., Nissen P., Penczek P., Grassucci R.A., Sweet R., Frank J., Moore P.B., and Steitz T.A. 1998. A $9 \AA$ resolution X-ray crystallographic map of the large ribosomal subunit. Cell 93: 1105.

Bilgin N. and Ehrenberg M. 1994. Mutations in 23 S ribosomal RNA perturb transfer RNA selection and can lead to streptomycin dependence. J. Mol. Biol. 235: 813.

Blundell T.L. and Johnson L.N. 1976. Protein crystallography. Academic Press, New York.

Brink M.F., Brink G., Verbeet M.P., and de Boer H.A. 1994. Spectinomycin interacts specifically with the residues G1064 and $\mathrm{C} 1192$ in $16 \mathrm{~S}$ rRNA, thereby potentially freezing this molecule into an inactive conformation. Nucleic Acids Res. 22: 325 .

Brodersen D.E., Clemons W.M., Carter A.P., Morgan-Warren R.J., Wimberly B.T., and Ramakrishnan V. 2000. The structural basis for the action of the antibiotics tetracycline, pactamycin, and hygromycin $\mathrm{B}$ on the $30 \mathrm{~S}$ ribosomal subunit. Cell 103: 1143.

Buck M.A. and Cooperman B.S. 1990. Single protein omission reconstitution studies of tetracycline binding to the $30 \mathrm{~S} \mathrm{sub}$ unit of Escherichia coli ribosomes. Biochemistry 29: 5374.

Carter A.P., Clemons W.M., Jr., Brodersen D.E., Morgan-Warren R., Wimberly B.T., and Ramakrishnan V. 2000. Functional insights from the structure of the $30 \mathrm{~S}$ ribosomal subunit and its interaction with antibiotics. Nature 407: 340.

Carter A.P., Clemons W.M., Jr., Brodersen D.E., Morgan-Warren R.J., Hartsch T., Wimberly B.T., and Ramakrishnan V. 2001. Crystal structure of an initiation factor bound to the $30 \mathrm{~S}$ ribosomal subunit. Science 291: 498.

Cate J.H., Yusupov M.M., Yusupova G.Z., Earnest T.N., and Noller H.F. 1999. X-ray crystal structures of 70S ribosome functional complexes (comments). Science 285: 2095.

Cate J.H., Gooding A.R., Podell E., Zhou K., Golden B.L., Kundrot C.E., Cech T.R., and Doudna J.A. 1996. Crystal structure of a group I ribozyme domain: Principles of RNA packing. Science 273: 1678.

Cheetham G.M. and Steitz T.A. 1999. Structure of a transcribing T7 RNA polymerase initiation complex. Science 286: 2305.

Chopra I. 1985. Mode of action of the tetracyclines and the nature of bacterial resistance to them. Handb. Exp. Pharmacol. 78: 317 .

Clemons W.M., Jr., May J.L.C., Wimberly B.T., McCutcheon J.P., Capel M., and Ramakrishnan V. 1999. Structure of a bacterial $30 \mathrm{~S}$ ribosomal subunit at $5.5 \AA$ resolution. Nature 400: 833.

Clemons W.M., Jr., Brodersen D.E., McCutcheon J.P., May J.L.C., Carter A.P., Morgan-Warren R.J., Wimberly B.T., and Ramakrishnan V. 2001. Crystal structure of the 30S ribosomal subunit from Thermus thermophilus: Purification, crystallization and structure determination. J. Mol. Biol. 310: 827 .

Crick F.H.C. 1966. Codon-anticodon pairing:The wobble hypothesis. J. Mol. Biol. 19: 548.

Crick F.H.C. and Magdoff B.S. 1956. The theory of the method of isomorphous replacement for protein crystals. I. Acta Crystallogr. 9: 901.

Dahlquist K.D. and Puglisi J.D. 2000. Interaction of translation initiation factor IF1 with the E. coli ribosomal A site. J. Mol. Biol. 299: 1.

Davies J., Gilbert W., and Gorini L. 1964. Streptomycin, suppression, and the code. Proc. Natl. Acad. Sci. 51: 883.

Doherty E.A., Batey R.T., Masquida B., and Doudna J.A. 2001. A universal mode of helix packing in RNA. Nat. Struct. Biol. 8: 339 .

Dontsova O., Dokudovskaya S., Kopylov A., Bogdanov A., Rinke-Appel J., Junke N., and Brimacombe R. 1992. Three widely separated positions in the 16S RNA lie in or close to the ribosomal decoding region; a site-directed cross-linking study with mRNA analogues. EMBOJ. 11: 3105 .

Doublie S., Tabor S., Long A.M., Richardson C.C., and Ellenberger T. 1998. Crystal structure of a bacteriophage T7 DNA replication complex at $2.2 \AA$ resolution. Nature 391: 251.
Eigen M. and De Maeyer L. 1966. Chemical means of information storage and readout in biological systems. Naturwissenschaften 53: 50.

Epe B., Woolley P., and Hornig H. 1987. Competition between tetracycline and tRNA at both $\mathrm{P}$ and A sites of the ribosome of Escherichia coli. FEBS Lett. 213: 443.

Fourmy D., Recht M.I., Blanchard S.C., and Puglisi J.D. 1996. Structure of the A site of Escherichia coli $16 \mathrm{~S}$ ribosomal RNA complexed with an aminoglycoside antibiotic. Science 274: 1367.

Frank J. and Agrawal R.K. 2000. A ratchet-like inter-subunit reorganization of the ribosome during translocation. Nature 406: 319

Frank J., Zhu J., Penczek P., Li Y., Srivastava S., Verschoor A., Radermacher M., Grassucci R., Lata R.K., and Agrawal R.K. 1995. A model of protein synthesis based on cryo-electron microscopy of the E. coli ribosome. Nature 376: 441.

Gabashvili I.S., Agrawal R.K., Grassucci R., Squires C.L., Dahlberg A.E., and Frank J. 1999. Major rearrangements in the $70 \mathrm{~S}$ ribosomal $3 \mathrm{D}$ structure caused by a conformational switch in 16S ribosomal RNA. EMBO J. 18: 6501.

Garman E. and Schneider. T.R. 1997. Macromolecular cryocrystallography. J. Appl. Crystallogr. 30: 211.

Garrett R.A., Douthwaite S.R., Liljas A., Matheson A.T., Moore P.B., and Noller H.F. 2000. The ribosome: Structure, function, antibiotics and cellular interactions. ASM Press, Washington, D.C.

Glotz C. and Brimacombe R. 1980. An experimentally-derived model for the secondary structure of the $16 \mathrm{~S}$ ribosomal RNA from Escherichia coli. Nucleic Acids Res. 8: 2377.

Glotz C., Müssig J., Gewitz H.S., Makowski I., Arad T., Yonath A., and Wittmann H.G. 1987. Three-dimensional crystals of ribosomes and their subunits from eu- and archaebacteria. Biochem. Int. 15: 953.

Godefroy-Colburn T., Wolfe A.D., Dondon J., Grunberg-Manago M., Dessen P., and Pantaloni D. 1975. Light-scattering studies showing the effect of initiation factors on the reversible dissociation of Escherichia coli ribosomes. J. Mol. Biol. 94: 461.

Gordon J. 1969. Hydrolysis of guanosine 5'-triphosphate associated wh binding of aminoacyl transfer ribonucleic acid to ribosomes. J. Biol. Chem. 244: 5680.

Gutell R.R. 1996. Comparative sequence analysis and the structure of 16S and 23S rRNA. In Ribosomal RNA: Structure, evolution, processing, and function in protein biosynthesis (ed. A.E. Dahlberg and R.A. Zimmermann), p. 111. CRC Press, Boca Raton, Florida.

Helliwell J.R. 1998. Synchrotron radiation facilities. Nat. Struct. Biol. (suppl.) 5: 614.

Hendrickson W.A. 1991. Determination of macromolecular structures from anomalous diffraction of synchrotron radiation. Science 254: 51.

2000. Synchrotron crystallography. Trends Biochem. Sci. 25: 637.

Hendrickson W.A., Horton J.R., and LeMaster D.M. 1990. Selenomethionyl proteins produced for analysis by multiwavelength anomalous diffraction (MAD): A vehicle for direct determination of three-dimensional structure. EMBO J. 9: 1665.

Hirsh D. 1971. Tryptophan transfer RNA as the UGA suppressor. J. Mol. Biol. 58: 439.

Hope H. 1988. Cryocrystallography of biological macromolecules: A generally applicable method. Acta Crystallogr. B 44: 22 .

Hope H., Frolow F., von Böhlen K., Makowski I., Kratky C., Halfon Y., Danz H., Webster P., Bartels K.S., Wittmann H.G., and Yonath A. 1989. Cryocrystallography of ribosomal particles. Acta Crystallogr. B 45: 190.

Hopfield J.J. 1974. Kinetic proofreading: A new mechanism for reducing errors in biosynthetic processes requiring high specificity. Proc. Natl. Acad. Sci. 71: 4135.

Kahn R., Fourme R., Bosshard R., Chiadmi M., Risler J.L., Dideberg O., and Wery J.P. 1985. Crystal structure study of Opsanus tau parvalbumin by multiwavelength anomalous diffraction. FEBS Lett. 179: 133. 
Kiefer J.R., Mao C., Braman J.C., and Beese L.S. 1998. Visualizing DNA replication in a catalytically active Bacillus DNA polymerase crystal. Nature 391: 304.

Knablein J., Neuefeind T., Schneider F., Bergner A., Messerschmidt A., Lowe J., Steipe B., and Huber R. 1997. $\operatorname{Ta} 6 \mathrm{Br}(2+) 12$, a tool for phase determination of large biological assemblies by X-ray crystallography. J. Mol. Biol. 270: 1 .

Kolesnikov I.V., Protasova N.Y., and A.T. Gudkov. 1996. Tetracyclines induce changes in accessibility of ribosomal proteins to proteases. Biochimie 78: 868 .

Kurland C.G. 1992. Translational accuracy and the fitness of bacteria. Annu. Rev. Genet. 26: 29.

Kurland C.G., Hughes D., and Ehrenberg M. 1996. Limitations of translational accuracy. In Escherichia coli and Salmonella typhimurium: Cellular and molecular biology, 2nd edition (ed. F.C. Neidhardt et al.), p. 979. ASM Press, Washington, D.C.

Lata K.R., Agrawal R.K., Penczek P., Grassucci R., Zhu J., and Frank J. 1996. Three-dimensional reconstruction of the Escherichia coli $30 \mathrm{~S}$ ribosomal subunit in ice. J. Mol. Biol. 262: 43.

Lodmell J.S. and Dahlberg A.E. 1997. A conformational switch in Escherichia coli 16S ribosomal RNA during decoding of messenger RNA. Science 277: 1262.

McCarthy B.J. and Holland J.J. 1965. Denatured DNA as a direct template for in vitro protein synthesis. Proc. Natl. Acad. Sci. 54: 880

Moazed D. and Noller H.F. 1987. Interaction of antibiotics with functional sites in 16S ribosomal RNA. Nature 327: 389.

. 1990. Binding of tRNA to the ribosomal A and P sites protects two distinct sets of nucleotides in $16 \mathrm{~S}$ rRNA. J. Mol. Biol. 211: 135 .

Moazed D., Samaha R.R., Gualerzi C., and Noller H.F. 1995. Specific protection of $16 \mathrm{~S}$ rRNA by translational initiation factors. J. Mol. Biol. 248: 207.

Mueller F., Stark H., van Heel M., Rinke-Appel J., and Brimacombe R. 1997. A new model for the three-dimensional folding of Escherichia coli $16 \mathrm{~S}$ ribosomal RNA. III. The topography of the functional centre. J. Mol. Biol. 271: 566.

Nierhaus K.H. 1990. The allosteric three-site model for the ribosomal elongation cycle: Features and future. Biochemistry 29: 4997.

Ninio J. 1975. Kinetic amplification of enzyme discrimination. Biochimie 57: 587.

Nissen P., Ippolito J.A., Ban N., Moore P.B., and Steitz T.A. 2001. RNA tertiary interactions in the large ribosomal subunit: The A-minor motif. Proc. Natl. Acad. Sci. 98: 4899.

Nowotny V. and Nierhaus K.H. 1988. Assembly of the 30S subunit from Escherichia coli ribosomes occurs via two assembly domains which are initiated by S4 and S7. Biochemistry 27: 7051 .

O'Connor M. and Dahlberg A.E. 1993. Mutations at U2555, a tRNA-protected base in 23S rRNA, affect translational fidelity. Proc. Natl. Acad. Sci. 90: 9214.

O'Connor M., Thomas C.L., Zimmermann R.A., and Dahlberg A.E. 1997. Decoding fidelity at the ribosomal A and P sites: Influence of mutations in three different regions of the decoding domain in 16S rRNA. Nucleic Acids Res. 25: 1185.

O'Connor M., Brunelli C.A., Firpo M.A., Gregory S.T., Lieberman K.R., Lodmell J.S., Moine H., Van Ryk D.I., and Dahlberg A.E. 1995. Genetic probes of ribosomal RNA function. Biochem. Cell Biol. 73: 859.

Ogle J.M., Brodersen D.E., Clemons W.M., Jr., Tarry M.J., Carter A.P., and Ramakrishnan V. 2001. Recognition of cognate transfer RNA by the 30 S ribosomal subunit. Science 292: 897.

O'Halloran T.V., Lippard S.J., Richmond T.J., and Klug A. 1987. Multiple heavy-atom reagents for macromolecular Xray structure determination. Application to the nucleosome core particle. J. Mol. Biol. 194: 705.

Pioletti M., Schlunzen F., Harms J., Zarivach R., Gluhmann M., Avila H., Bashan A., Bartels H., Auerbach T., Jacobi C., Hartsch T., Yonath A., and Franceschi F. 2001. Crystal structures of complexes of the small ribosomal subunit with tetra- cycline, edeine and IF3. EMBO J. 20: 1829.

Potapov A.P. 1982. A stereospecific mechanism for the aminoacyl-tRNA selection at the ribosome. FEBS Lett. 146: 5.

Potapov A.P., Triana-Alonso F.J., and Nierhaus K.H. 1995. Ribosomal decoding processes at codons in the A or P sites depend differently on 2'-OH groups. J. Biol. Chem. 270: 17680.

Powers T. and Noller H.F. 1994. Selective perturbation of G530 of $16 \mathrm{~S}$ rRNA by translational miscoding agents and a streptomycin-dependence mutation in protein S12. J. Mol. Biol. 235: 156.

Purohit P. and Stern S. 1994. Interactions of a small RNA with antibiotic and RNA ligands of the 30S subunit. Nature 370: 659.

Ramakrishnan V. and Biou V. 1997. Treatment of multiwavelength anomalous diffraction data as a special case of multiple isomorphous replacement. Methods Enzymol. 276: 538.

Ramakrishnan V., Finch J.T., Graziano V., Lee P.L., and Sweet R.M. 1993. Crystal structure of globular domain of histone $\mathrm{H} 5$ and its implications for nucleosome binding. Nature 362: 219.

Rodnina M.V. and Wintermeyer W. 2001. Ribosome fidelity: tRNA discrimination, proofreading and induced fit. Trends Biochem. Sci. 26: 124.

Ruusala T. and Kurland C.G. 1984. Streptomycin preferentially perturbs ribosomal proofreading. Mol. Gen. Genet. 198: 100 .

Ruusala T., Ehrenberg M., and Kurland C.G. 1982. Is there proofreading during polypeptide synthesis? EMBO J. 1: 741.

Schluenzen F., Tocilj A., Zarivach R., Harms J., Gluehmann M., Janell D., Bashan A., Bartels H., Agmon I., Franceschi F., and Yonath A. 2000. Structure of functionally activated small ribosomal subunit at $3.3 \AA$ resolution. Cell 102: 615 .

Schluenzen F., Hansen H.A.S., Thygesen J., Bennett W.S., Volkmann N., Levin I., Harms J., Bartles H., Zaytzev-Bashan A., Berkovitch-Yellin Z., Sagi I., Fransceschi F., Krumbholtz S., Geva M., Weinstein S., Agmon I., Boddeker N., Morlang S., Sharon R., Dribin A., Maltz E., Peretz M., Weinrich V., and Yonath A. 1995. A milestone in ribosomal crystallography: The construction of preliminary electron density maps at intermediate resolution. Biochem. Cell Biol. 73: 739.

Sigmund C.D., Ettayebi M., and Morgan E.A. 1984. Antibiotic resistance mutations in $16 \mathrm{~S}$ and $23 \mathrm{~S}$ ribosomal RNA genes of Escherichia coli. Nucleic Acids Res. 12: 4653.

Spahn C.M. and Prescott C.D. 1996. Throwing a spanner in the works: Antibiotics and the translation apparatus. J. Mol. Med. 74: 423.

Stark H., Rodnina M.V., Rinke-Appel J., Brimacombe R., Wintermeyer W., and van Heel M. 1997. Visualization of elongation factor Tu on the Escherichia coli ribosome. Nature 389: 403.

Stark H., Mueller F., Orlova E.V., Schatz M., Dube P., Erdemir T., Zemlin F., Brimacombe R., and van Heel M. 1995. The 70S Escherichia coli ribosome at 23 Å resolution: Fitting the ribosomal RNA. Structure 3: 815.

Tapio S. and Isaksson L.A. 1988. Antagonistic effects of mutant elongation factor Tu and ribosomal protein S12 on control of translational accuracy, suppression and cellular growth. Biochimie 70: 273.

Thompson R.C. and Dix D.B. 1982. Accuracy of protein biosynthesis. A kinetic study of the reaction of poly(U)-programmed ribosomes with a leucyl-tRNA2-elongation factor Tu-GTP complex. J. Biol. Chem. 257: 6677.

Thompson R.C. and Karim A.M. 1982. The accuracy of protein biosynthesis is limited by its speed: High fidelity selection by ribosomes of aminoacyl-tRNA ternary complexes containing GTP $\gamma$ S. Proc. Natl. Acad. Sci. 79: 4922.

Thompson R.C. and Stone P.J. 1977. Proofreading of the codonanticodon interaction on ribosomes. Proc. Natl. Acad. Sci. 74: 198.

Thygesen J., Weinstein S., Franceschi F., and Yonath A. 1996. The suitability of multi-metal clusters for phasing in crystallography of large macromolecular assemblies. Structure 4: 513.

Tocilj A., Schlunzen F., Janell D., Gluhmann M., Hansen H.A., Harms J., Bashan, Bartels H., Agmon I., Franceschi F., and 
Yonath A. 1999. The small ribosomal subunit from Thermus thermophilus at $4.5 \AA$ A resolution: Pattern fittings and the identification of a functional site. Proc. Natl. Acad. Sci. 96: 14252.

Trakhanov S.D., Yusupov M.M., Agalarov S.C., Garber M.B., Ryazantsev S.N., Tischenko S.V., and Shirokov V.A. 1987. Crystallization of $70 \mathrm{~S}$ ribosomes and $30 \mathrm{~S}$ ribosomal subunits from Thermus thermophilus. FEBS Lett. 220: 319.

VanLoock M.S., Easterwood T.R., and Harvey S.C. 1999. Major groove binding of the tRNA/mRNA complex to the $16 \mathrm{~S}$ ribosomal RNA decoding site. J. Mol. Biol. 285: 2069.

von Böhlen K., Makowski I., Hansen H.A.S., Bartels H., Berkovitch-Yellin Z., Zaytzev-Bashan A., Meyer S., Paulke C., Franceschi F., and Yonath A. 1991. Characterization and preliminary attempts for derivatization of crystals of large ribosomal subunits from Haloarcula marismortui diffracting to 3 Å resolution. J. Mol. Biol. 222: 11.

Weis W.I., Kahn R., Fourme R., Drickamer K., and Hendrickson W.A. 1991. Structure of the calcium-dependent lectin domain from a rat mannose-binding protein determined by MAD phasing. Science 254: 1608.

Wimberly B.T., Brodersen D.E., Clemons W.M., Jr., MorganWarren R., von Rhein C., Hartsch T., and Ramakrishnan V. 2000. Structure of the 30S ribosomal subunit. Nature 407: 327.

Yokoyama S. and Nishimura S. 1995. Modified nucleosides and codon recognition. In tRNA: Structure, biosynthesis and function (ed. D. Söll and U. RajBhandary), p. 207. ASM Press, Washington, D.C.

Yonath A., Mussig J., Tesche B., Lorenz S., Erdmann V.A., and
Wittmann H.G. 1980. Crystallization of the large ribosomal subunits from Bacillus stearothermophilus. Biochem. Int. 1: 428.

Yonath A., Glotz C., Gewitz H.S., Bartels K.S., von Böhlen K., Makowski L., and Wittmann H.G. 1988. Characterization of crystals of small ribosomal subunits. J. Mol. Biol. 203: 831.

Yonath A., Harms J., Hansen H.A., Bashan A., Schlunzen F., Levin I., Koelln I., Tocilj A., Agmon I., Peretz M., Bartels H., Bennett W.S., Krumbholz S., Janell D., Weinstein S., Auerbach T., Avila H., Piolleti M., Morlang S., and Franceschi F. 1998. Crystallographic studies on the ribosome, a large macromolecular assembly exhibiting severe nonisomorphism, extreme beam sensitivity and no internal symmetry. Acta Crystallogr. A 54: 945.

Yoshizawa S., Fourmy D., and Puglisi J.D. 1998. Structural origins of gentamicin antibiotic action. EMBO J. 17: 6437.

1999. Recognition of the codon-anticodon helix by ribosomal RNA. Science 285: 1722.

Yusupov M.M., Tischenko S.V., Trakhanov S.D., Ryazantsev S.N., and Garber M.B. 1988. A new crystalline form of $30 \mathrm{~S}$ ribosomal subunits from Thermus thermophilus. FEBS Lett. 238: 113

Yusupov M.M., Yusupova G.Z., Baucom A., Lieberman K., Earnest T.N., Cate J.H., and Noller H.F. 2001. Crystal structure of the ribosome at $5.5 \AA$ resolution. Science 292: 883.

Yusupov M.M., Trakhanov S.D., Barynin V.V., Borovyagin V.L., Garber M.B., Sedelnikova O.M., Tishchenko S.V., and Shirokov V.A. 1987. Crystallization of 30S ribosomal subunits from T. thermophilus. Dokl. Akad. Nauk USSR 292: 1271. 